\title{
AC 2008-104: IMPACT OF UNDERGRADUATE ROBOTICS RESEARCH ON RECRUITING FRESHMAN STUDENTS TO MAJOR IN ENGINEERING PHYSICS, AND COMPUTER SCIENCE FIELDS
}

Baha Jassemnejad, University of Central Oklahoma

Wei Pee, University of Central Oklahoma

Engineering Lab Associate

Mathew Mounce, University of Central Oklhoma

Student 


\title{
The Role of Designing Robots to Promote the Interest of Incoming College Freshman Students to Major in Engineering and Computer Science Field
}

\begin{abstract}
The goal of this robotic research activity in the UCO's Engineering and Physics department was to promote science, technology, engineering, and mathematics (STEM ) among the incoming freshmen so that they will be encouraged to pursue a degree in Engineering, Physics, or computer science. The duration of this research activity was four weeks, during which time these students become familiar with research, teamwork, problem based learning, and the procedures involved in engineering design and building. The first phase of the activity, lasting for one week, involved an introduction to basic theory focusing on electronics, mechanics, programming, and engineering design processes. The second phase of the activity, lasting the remaining three weeks, involved researching, designing, and building a conceptual model and prototype of a minesweeper robot. With the facilitation of their peer mentors, students built a working scaled down model that could autonomously navigate, identify, and extract mines. Following the presentation of their project, these students expressed enthusiasm in pursuing a degree in engineering physics and computer science disciplines.
\end{abstract}

\section{Introduction}

The National science foundation and the International Association for the Evaluation of Educational Achievement reported that America is below average in science and mathematics education when compared to other countries. When comparing U.S. K-12 students to their international counterparts, a trend emerged. While U.S. students in the 4th and 8th grades score in the top percentile, 12 th graders score at the bottom in math and science ${ }^{1}$. Without a strong background in mathematics and science, college freshmen face a more difficult time in their first year of college which leads to many science, computer science, and engineering majors changing their majors or quit college all together. For example, when examining the number of people graduating with bachelor degrees in engineering, the United States falls behind other countries. Even though we have the largest world economy and the fourth largest country by population, it only ranks sixth in the number of bachelor degrees awarded in engineering in 2000, reported by the National Science Foundation with the most recent comparable data available. China graduates almost four times as many engineers as the United States. Japan with less than half of the population of the United States, graduates almost twice as many engineers ${ }^{2}$. This is a crisis that has to be addressed and many organizations are trying to work towards increasing the number of STEM bachelor degrees awarded. The national science foundation in coordination with universities has developed a program called Summer Bridge. The goal of the Summer Bridge Program is to provide an intensive, four-week, enrichment experience to incoming STEM majors. It is designed to bridge the gap between high school and college by offering tools needed to help students succeed and graduate. The aim of our Department for the summer of 2007 was to develop a method through robotics research to increase student interest in STEM as well in 
pursuing Engineering, Physics, Computer Science, and Mathematics as majors. The area of Robotics was chosen since it embodies all the areas of STEM.

To address the issue of lack of interest in STEM by students, government agencies such as NSF and NASA have provided funding research activities. This is aimed at not only recruit students to STEM disciplines but also retain them. A number of researchers have utilized robotics to achieve this aim. ${ }^{3-10}$ While majority of those studies focus on STEM education and retention at k-12, we focused on incoming college freshman that have an interest in STEM. The belief is incoming freshman that have interest in science and engineering, but not the skills or discipline, can be successful in those majors regardless of race, gender, or socioeconomic background.

\section{Method}

The method of teaching the students was very important since the time available to give the students the skills required to do hands-on robotics research was very limited. The program lasted four weeks and the students were only required to spend 4 hours a day, Monday thru Thursday, researching and completing their project. Also, since all of them were incoming freshman and had little to no knowledge in the area of robotics, we had to develop an efficient method of teaching the students the basics of mechanics, electronics, and the engineering design process that would still allow them to complete a fully functional robot in such a short time frame. It was very import that the students finished the program with a complete functional robot, and not leave without having accomplished what they set out to do. We decided to break up the four week program into two phases. The first phase of the program lasted only five days and consisted of an intense introduction into the basics of robotics while focusing heavily on the engineering design process. The second phase, lasting 13 days, was an implementation of the skills learned in phase I. For the second phase, the students were given a goal, which they had to be completed by the end of the fourth week, at which time they would present their work to faculty and students.

Phase I was divided into three sections. The first section taught them the engineering design process, how to work as a team, and time management. The second section taught them the basics of motors, sensors, gears, and data acquisition. We utilized a very powerful but under rated tool in robotics education; the Lego Mindstorm NXT controller and accompanying motors and sensors. This robotics platform allowed the students to experience robotics and the engineering process; but at the same time did not require them to know high level programming languages and electronics that is very much a part of robotics. In the third section we formed two teams, students each. They were given a goal, which was to develop a better or more marketable mine sweeper robot prototype based on their research of current mine sweeper designs. They used Legos, the NXT controller, and the available sensors t such as color sensors, ultrasonic sensors, and compass sensors. The goals were allowed to be very flexible so as to give the students the chance to use their imagination and fully experience the brainstorming process.

Phase II was conducted in 13 days; during which time students were involved designing a conceptual working model of a mind sweeper robot. Since the students had learned, through lectures and hand outs, the engineering design process and other required skills needed to produce a working model, they exhibited confident toward their conceptual working model. 
They were encouraged to brainstorm and propose any ideas they arrived at to their mentors before continuing.

\section{Observations and Results}

Phase I was an introduction to basic theory of robot design and the engineering process. The first day was three hours of lecture covering Topics such as the engineering process, electronics, mechanics, and programming. Emphasis was placed on the engineering process. The second day the students were divided into two person teams. Each team was given brief lectures and hands on activities with the aid of specific tutorials designed to give them required skills in the areas of mechanics, programming, and data acquisition. The idea was in order for them to be successful in a larger team, the students were taught to operate in the smaller teams. The student mentors acted as project managers and where involved in the design process of all three teams. The three student teams spent all day completing their prototypes built using Legos. At the end of the day all teams presented their findings and prototypes through a power point presentation. Following the presentation,, the student mentors took the three individual teams and formed one large team. Task assignment and respective roles for each student were mad; and the student mentors resigned from the duties as project manager.

The beginning of Phase II was more difficult for the students. As they continued with the process, the team encountered many problems such as the design of the gear box for the treads connecting the wheels, and the autonomous navigation program that allowed the robot to orientate itself as it looked for mines were challenging. Although at first, they seemed over whelmed and felt as though this project was doomed, their peer mentors helped them along and they soon realized these types of problems and failures are common. The idea that "failure happens" was a great stride in increasing their confidence; and they began to enjoy the challenge of their project that just days before seemed impossible.

Due to the lack of their skills in computer aided drafting and simulation software, many of them were unable to utilize such technology and had to use other methods of design. They made hand drawings and card board models of their designs before they built them using raw materials. This was a great experience for them and was an insight into the many tools an engineer uses to create even the simplest prototypes.

The team redesigned and improved their robot as they went through the engineering design process. They began asking for raw materials such as aluminum and plastic to make custom parts for their robot. The mentors facilitated the team by building these custom parts using university's CNC milling machine and machine shop. By the end of the program the group of six students had built a conceptual mine sweeper robot that could locate and extract mines, which were colored metal disc about the size of a silver dollar. The robot had 7 electric motors, a compass sensor, ultrasonic sensor, color sensor, 88 bolts to hold it together, and treads with a custom built gear box.

The team kept an engineering journal which they maintained every day. With this journal they were able to document the design, building, and testing of their robot. Charts 1 and 2, Gantt chart 
and testing data respectively, are two examples of what they recorded in their journal. The practice of keeping their engineering journal was difficult for them at first but with constant reminder and the need for them to refer back to their activities they learned quickly journals are an invaluable tool for building as well as later analysis of their progress.

\section{Gantt Chart}

\begin{tabular}{|l|l|l|l|}
\hline Week 1 & Week 2 & Week 3 & Week 4 \\
\hline Define Problem & $\begin{array}{l}\text { Research- } \\
\text { Brainstorm } \\
\text { Full Design }\end{array}$ & $\begin{array}{l}\text { Redesign } \\
\text { Computer } \\
\text { Arrangement }\end{array}$ & $\begin{array}{l}\text { Build Claw/Forklift } \\
\text { Mechanism }\end{array}$ \\
\hline $\begin{array}{l}\text { Research Current } \\
\text { Designs }\end{array}$ & $\begin{array}{l}\text { Begin Building } \\
\text { Final Design }\end{array}$ & $\begin{array}{l}\text { Build Front } \\
\text { Wheels and } \\
\text { Attach to base }\end{array}$ & $\begin{array}{l}\text { Test and } \\
\text { Redesign } \\
\text { Communication }\end{array}$ \\
\hline Brainstorm Ideas & Base of Robot & $\begin{array}{l}\text { Redesign Treads } \\
\text { and attach to } \\
\text { Base x 3 }\end{array}$ & $\begin{array}{l}\text { Test and } \\
\text { Redesign } \\
\text { Avoidance }\end{array}$ \\
\hline Build Prototypes & Build Treads & $\begin{array}{l}\text { Redesign NXT-1 } \\
\text { Program }\end{array}$ & $\begin{array}{l}\text { Test and calibrate } \\
\text { sensors }\end{array}$ \\
\hline & NXT-1 Program & NXT 2-3 Program & \\
\hline
\end{tabular}

Chart 1 - Students' Gantt Chart which they recorded in their engineering journals 


\section{Testing the Robot}

- Sensor readings were collected by logging the data in files created in the program as it swept for mines and obstacles.
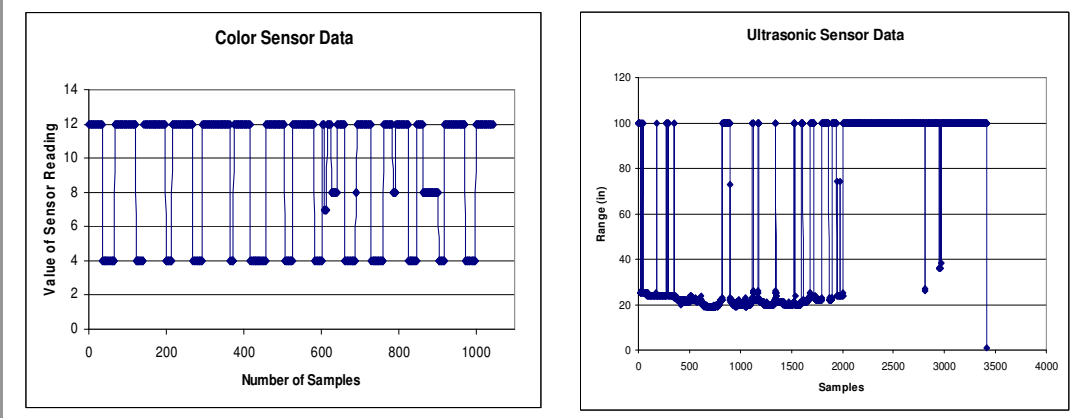

Simulates metal detector to detect mines

A value of around 8 indicates a mine has been detected

Chart 2 - Some data recorded by the team as they tested their mine sweeping robot

\section{Conclusions}

After the intensive four weeks, the robotics research project received overwhelming response from faculty members and students in the STEM program. To this end this project was among those that were recommended to be showcased due to its positive impact on the participating students. All the students in the robotics research program felt more confident and determined to pursue their bachelor degrees in Engineering, Physics, and Computer Science.

\section{References}

1. International Association for the Evaluation of Educational Achievement, Third International Mathematics and Science Study (TIMSS).

2. U.S. National Science Foundation, Science \& Engineering Indicators (2004), Appendix 2-33; and IMD World Competitiveness Yearbook (2004).

3. Zeid, Ibrahim, Randal August, and Ronald Perry. "A Partnership to Integrate Robotics Curriculum Into STEM Courses in Boston Public Schools." American Society for Engineering Education (2007). 
4. Hwang, William, Ahrash Bissell, and Daniel Kaplan. "Design and Evaluation of InnoWorks:a Portable, Interdisciplinary Science and Engineering Program by Volunteer College Students for Middle School Youth From Underprivileged Backgrounds." American Society for Engineering Education (2006 - 1086).

5. Designing, Developing and Implementing a Course on LEGO Robotics for Technology Teacher Education Journal article by Joan M. Chambers, Mike Carbonaro; Journal of Technology and Teacher Education, Vol. 11, 2003

6. Nourbakhsh, I., Crowley, K., Bhave, A., Hamner, E., Hsium, T., Perez-Bergquist, A., Richards, S., \& Wilkinson, K. (2005). The robotic autonomy mobile robots course: Robot design, curriculum design, and educational assessment. Autonomous Robots, 18(1), 103127.

7. Robinson, M. (2005). Robotics-driven activities: Can they improve middle school science learning? Bulletin of Science, Technology \& Society, 25(1), 73-84.

8. Beer, R. D., Chiel, H. J., \& Drushel, R. F. (1999). Using robotics to teach science and engineering. Communications of the ACM, 42(6), 85-92.

9. Maja J Matari'c. Robotics education for all ages. In AAAI Spring Symposium on Accessible, Hands-on AI and Robotics Education, Palo Alto, CA, March 22-24 2004.

10. Autonomous Robots as a Generic Teaching Tool Howell, A.; Way, E.; Mcgrann, R.; Woods, R. Frontiers in Education Conference, 36th Annual Volume, Issue , 27-31 Oct. 2006 Page(s): $17-21$.

\section{Acknowledgments}

Michael Gasperi, Isabella L. Hurbain, and Philippe E. Hurbain. 2007. Extreme NXT: Extending the LEGO MINDSTORMS NXT to the Next Level. Apress

James Floyd Kelly. 2006. Lego Mindstorms NXT: The Mayan Adventure (Technology in Action). Apress

Matthias Paul Scholz. 2007. Advanced NXT: The Da Vinci Inventions Book (Technology in Action). Apress

This project was funded by NSF SURE-STEP Summer Bridge Program. 